\title{
Orthodontic treatment for disabled children: a survey of parents' attitudes and overall satisfaction
}

\author{
María Teresa Abeleira ${ }^{1,2}$, Elisabeth Pazos ${ }^{2}$, Isabel Ramos ${ }^{2,3}$, Mercedes Outumuro ${ }^{2,4}$, Jacobo Limeres ${ }^{1,2,4}$, \\ Juan Seoane-Romero ${ }^{2}$, Marcio Diniz ${ }^{2,4}$ and Pedro Diz ${ }^{2,4^{*}}$
}

\begin{abstract}
Background: Many patients with disability require orthodontic treatment (OT) to achieve adequate oral function and aesthetic appearance. The cooperation of disabled patients and of their parents is central to the success of OT, as treatment can involve ethical dilemmas. The aim of this study was to analyze the motivation, expectations and overall satisfaction with OT among parents of patients with disabilities.

Methods: The parents of 60 disabled Spanish children with physical, mental and/or sensory impairment undergoing OT were surveyed on attitudes to OT and level of satisfaction with the outcomes. The survey consisted of 23 questions in 4 sections: attitude and adaptation, benefits, adverse effects, and level of satisfaction after completion of OT. A control group formed of the parents of 60 healthy children undergoing OT at the same institution were also surveyed.

Results: Parents of disabled children undergoing OT showed a high level of motivation and they are willing to collaborate in oral hygiene procedures. Adaptation to the removable appliances was poorer in disabled children but adaptation to fixed appliances was excellent. OT can provide a marked improvement in quality of life, social relationships and oral functionality in disabled children.

Conclusions: Among parents of disabled children undergoing OT, the perceived level of overall satisfaction was very high and expectations were often exceeded.
\end{abstract}

Keywords: Disabled, Special needs, Orthodontic, Dentistry, Satisfaction

\section{Background}

Orthodontics and Dentofacial Orthopedics is "the dental specialty that includes the diagnosis, prevention, interception and correction of malocclusion, including neuromuscular and skeletal abnormalities of the developing or mature orofacial structures" [1]. The prevalence of severe malocclusion is particularly high among individuals with physical and/or mental disabilities [2,3].

Not only do orthodontic alterations compromise oral function, they also represent an obstacle to the social acceptance of physically and learning disabled persons

\footnotetext{
*Correspondence: pedro.diz@usc.es

OMEQUI Research Group, Santiago de Compostela University, Santiago de

Compostela, Spain

${ }^{4}$ Special Needs Unit, School of Medicine and Dentistry, Santiago de

Compostela University, Santiago de Compostela, Spain

Full list of author information is available at the end of the article
}

from an aesthetic point of view [4-6]. It has been estimated that approximately $75 \%$ of patients with disability require orthodontic treatment (OT) to achieve and maintain an optimal occlusal relationship necessary to ensure adequate oral function and aesthetic appearance $[5,6]$. The cooperation of disabled patients and of their parents is central to the success of OT [7], as treatment can involve ethical dilemmas that have been discussed in detail elsewhere [8].

The OT of disabled patients has been examined in a number of case reports and case series in the literature [9-11]. Parents play an important role in the uptake of orthodontic care and are the single most important factor in the motivation for treatment [12]. Our literature search has revealed very few studies that have analyzed the factors conditioning the response to OT and the 
parents' attitudes to orthodontic care, and none of those studies has included a control group of non-disabled individuals [13-15].

The aim of our study was to analyze the motivation and expectations of parents regarding the OT of disabled patients, the social implications, the adverse effects of therapy and the level of satisfaction with treatment outcomes.

\section{Methods}

The parents of 60 disabled children (DCh) with physical, mental and/or sensory impairment undergoing OT were surveyed on attitudes to OT and the level of satisfaction with outcomes. All treatments were performed between 2010 and 2013 in the Special Needs Unit of the School of Medicine and Dentistry of the University of Santiago de Compostela in Spain. The mean age of patients was $13.8 \pm 2.3$ years (range, 9-18 years). All patients lived at home or in an institution and no overnight stays in our unit were required. All patients were able to tolerate dental procedures using only behavior modification techniques; a single session of deep sedation or general anesthesia was needed in only 4 DCh patients for long procedures requiring a high degree of collaboration (taking impressions and bracket adhesion). Patients with severe malocclusions requiring jaw surgery were excluded.

The orthodontic diagnosis was established in each patient based on the following variables: anteroposterior malocclusion (Angle's classification system), transverse malocclusion, and pre-treatment Peer Assessment Rating (PAR) index. The orthodontic treatment outcome was evaluated by using the difference between pre-treatment and post-treatment PAR index scores (absolute value and percentage), and the PAR nomogram (worse or no different, improved, greatly improved).

The medical diagnoses in the study group were Down's syndrome (13 cases), mental and/or psychomotor deficiency (12 cases), congenital malformations with craniofacial involvement (10 cases), cerebral palsy (7 cases), autistic spectrum disorders (4 cases), sensory deficiencies (4 cases) and other rare congenital disorders (10 cases).

The survey was based on previously validated questionnaires [13-15], and consisted of 23 questions grouped into 4 sections (Spanish version, see Additional file 1).

1. Attitude and adaptation to OT: Patient attitude and parent capacity to help with oral care during treatment, frequency of daily toothbrushing, level of collaboration with oral hygiene procedures, adaptation to fixed and removable appliances and influence of treatment on activities of daily living.

2. Benefits derived from OT: Improvement in quality of life, social acceptance and integration, importance of aesthetic appearance and other reasons for seeking treatment.

3. Adverse effects associated with OT: Oral lesions, altered oral function, increased salivary secretion and nausea.

4. Level of satisfaction after completion of OT: Satisfaction with the outcome, improved self-image, reaction of family and friends, improvement in daily activities, changes in social life, and willingness to undergo orthodontic treatment again in the future should it be required.

To establish a control group, the parents of 60 healthy children $(\mathrm{HCh})$ undergoing $\mathrm{OT}$ at the Orthodontic Unit of the same institution and treated by the same orthodontists were also surveyed. HCh were matched with the DCh group for age, sex, anteroposterior malocclusion and pretreatment PAR index score. All patients (DCh and $\mathrm{HCh}$ ) were treated with both removable and fixed appliances.

The statistical analysis of the results was performed using $\mathrm{R}$ software, version 2.12.0 ( $\mathrm{R}$ Development Core Team, Vienna, Austria). Differences between the responses of DCh and $\mathrm{HCh}$ parents were analyzed using the Fisher test with significance taken as a $P$ value less than 0.05 . The Kruskal Wallis test was used to analyse differences in the values of the qualitative variables between patients with different medical diagnoses.

\section{Ethics and consent}

The study protocol was approved by the Ethics Committee of the University of Santiago de Compostela (reference number 2010-1724B). Written informed consent was obtained from the parents or legal guardians, as applicable, of the involved disabled and healthy children undergoing orthodontic treatment. A copy of the written consent is available for review by the Editor of this journal.

\section{Results}

\section{Orthodontic diagnoses}

The anteroposterior malocclusion diagnosis in the DCh group was Class I in $25.3 \%$ of cases, Class II in $33.7 \%$, and Class III in the remaining $41 \%$; the malocclusion was due to alterations in the maxilla in $13.2 \%$ of cases, alterations in the mandible in $13.2 \%$ of cases, and bimaxillary in $73.6 \%$. Transverse occlusal alterations were observed in $49 \%$ of the DCh group: unilateral crossbite in $21 \%$ and bilateral crossbite in $27.8 \%$. The mean PAR index score was $31.6 \pm 7$ pre-treatment and $10.4 \pm 8.4$ posttreatment. The mean difference between pre-treatment and post-treatment PAR was $21.2 \pm 5(69.9 \pm 20.1 \%)$; after OT, $39.8 \%$ of DCh parents considered that there had been a marked improvement, $54.2 \%$ that their child had improved, and $6 \%$ that treatment had not produced any improvement. 
No differences were detected in the distribution of anteroposterior malocclusions or in the pre-treatment PAR index scores between the DCh and the matched $\mathrm{HCh}$.

The medical diagnosis of the patients influenced the prevalence of anteroposterior malocclusions $(P=0.02)$ (Table 1). However, it did not affect the prevalence of transverse malocclusions, the distribution of maxillary, mandibular, or bimaxillary alterations, pre-treatment PAR, post-treatment PAR, difference between pre-treatment and post-treatment PAR, or the PAR nomogram.

\section{Attitudes and adaptation}

According to parents, $83.3 \%$ of DCh were particularly motivated during therapy. A large majority (91.6\%) of DCh parents felt fully prepared to perform oral care during OT compared with $60.0 \%$ of $\mathrm{HCh}$ parents, $40.0 \%$ of whom admitted that they were not ready $(P<0.001)$. An increase in daily toothbrushing was detected in $55.0 \%$ of DCh, and $66.6 \%$ of these patients performed this activity 2 to 3 times a day. A high level of collaboration in daily oral hygiene procedures was reported by $60.0 \%$ of the parents of DCh (even prior to OT) in contrast to $1.6 \%$ of $\mathrm{HCh}$ parents, and $83.3 \%$ of $\mathrm{HCh}$ showed a poor collaboration in these procedures $(P<0.001)$. Adaptation to wearing removable appliances was poorer in DCh than in $\mathrm{HCh}(71.4 \%$ versus $93.8 \%, P=0.019)$, and $11.9 \%$ of DCh did not tolerate the appliance. Adaptation to fixed appliances was excellent in both the DCh and the HCh groups (91.6\% and $100 \%$, respectively). While $36.6 \%$ of DCh parents agreed that no individual phase of OT was more difficult than the other stages, $51 \%$ of $\mathrm{HCh}$ parents suggested that the fixed appliance phase offered the greatest difficulty $(P<0.001)$. The maintenance of oral hygiene during OT was considered particularly stressful by $46.6 \%$ of DCh parents compared with $85 \%$ HCh parents $(P<0.001)$. These results are detailed in Table 2 .

\begin{tabular}{|c|c|c|c|}
\hline Medical diagnoses & Class I & Class II & Class III \\
\hline Down's syndrome & 0 & 1 & 12 \\
\hline Mental and/or psychomotor deficiency & 4 & 3 & 5 \\
\hline $\begin{array}{l}\text { Congenital malformations with } \\
\text { craniofacial involvement }\end{array}$ & 1 & 5 & 4 \\
\hline Cerebral palsy & 0 & 5 & 2 \\
\hline Autistic spectrum disorders & 0 & 2 & 2 \\
\hline Sensory deficiencies & 1 & 0 & 3 \\
\hline Other rare congenital disorders & 3 & 3 & 4 \\
\hline
\end{tabular}

\section{Perceived benefits of OT}

An improvement in the quality of life of the child after OT was reported by $83.3 \%$ of DCh parents compared with $78.3 \%$ of $\mathrm{HCh}$ parents (not significant). However, while $78.3 \%$ of DCh parents considered that OT had improved social acceptance and $71.6 \%$ that it had increased social integration, each of these changes was only reported by $55.0 \%$ of $\mathrm{HCh}$ parents $(P=0.016$ and $P=0.006$, respectively). The reason that DCh parents requested OT was to improve dental health in $53.3 \%$ and to improve speech in $21.6 \%$, compared to $75.0 \%$ and $1.6 \%$, respectively, among HCh parents $(P=0.002)$. These results are detailed in Table 3 .

\section{Adverse effects associated with OT}

Oral lesions were detected by $59.9 \%$ of DCh parents during OT. In most patients $(76.6 \%$ of DCh and $85.0 \%$ of $\mathrm{HCh}$ ) the appliances did not alter everyday oral function. An increase in saliva production and/or nausea was observed in $20.0 \%$ of DCh compared with $5.0 \%$ of HCh $(P=0.008)$. "Alteration of everyday oral function" was more common among patients with the highest post-treatment PAR scores $(P=0.04)$ and those with the largest differences between pre-treatment and posttreatment PAR scores $(P=0.03)$. These results are detailed in Table 4.

\section{Satisfaction and improvements}

Satisfaction with the outcomes of OT was indicated by $51.5 \%$ of DCh parents and $42.4 \%$ of them stated that the results exceeded expectations, compared with $90.0 \%$ and $10.0 \%$, respectively, of $\mathrm{HCh}$ parents $(P<0.001)$. Results exceeded expectations particularly in patients with the highest pre-treatment PAR scores $(P=0.02)$, and those with highest differences between pre-treatment and posttreatment PAR scores $(P=0.03)$.

Relatives and friends got excited about OT results in $54.5 \%$ of DCh patients whereas no reaction was observed in $71.6 \%$ of the $\mathrm{HCh}$ group $(P<0.001)$. The percentage of relatives who were enthusiastic about OT outcomes was higher among patients with the highest pre-treatment PAR scores $(P=0.02)$, those with greatest differences between pre-treatment and post-treatment PAR scores $(P<0.01)$, and those with a marked improvement on the PAR nomogram $(P=0.01)$.

The number of parents who observed a significant improvement in daily activities and social life after OT was significantly higher among DCh $(81.8 \%$ and $45.4 \%)$ than among HCh $(10.0 \%$ and $5.0 \%)(P<0.001$ in both groups). Improvement in patient daily activities was most evident among patients with the highest pre-treatment PAR scores $(P<0.01)$, and those with the greatest differences between pre-treatment and post-treatment PAR scores $(P=0.02)$. Improvement in patient's social life increased 
Table 2 Opinions of parents of disabled $(n=60)$ and healthy children $(n=60)$ on attitudes and adaptation to appliances during orthodontic treatment

\begin{tabular}{|c|c|c|c|}
\hline & $\begin{array}{l}\text { Disabled children } \\
\mathrm{n}(\%)\end{array}$ & $\begin{array}{l}\text { Healthy children } \\
\mathrm{n}(\%)\end{array}$ & $P$ value \\
\hline Patient's attitude & & & 1.000 \\
\hline She/he was particularly motivated during therapy & $50(83.3 \%)$ & $52(86.6 \%)$ & \\
\hline She/he understood the therapy, but was not motivated & $5(8.3 \%)$ & $8(13.3 \%)$ & \\
\hline She/he did not understand the therapy & $5(8.3 \%)$ & $0(0 \%)$ & \\
\hline Parent's preparation for oral care & & & $<0.001$ \\
\hline Fully prepared & $55(91.6 \%)$ & $36(60.0 \%)$ & \\
\hline Ready to act if necessary & $2(3.3 \%)$ & $0(0 \%)$ & \\
\hline Prepared to guide and encourage caregivers & $1(1.6 \%)$ & $0(0 \%)$ & \\
\hline Not ready & $2(3.3 \%)$ & $24(40.0 \%)$ & \\
\hline Daily toothbrushing & & & 0.154 \\
\hline Increased & $33(55.0 \%)$ & $25(41.6 \%)$ & \\
\hline Not increased & $27(45.0 \%)$ & $35(58.3 \%)$ & \\
\hline Number of daily toothbrushings before orthodontic treatment & & & 0.812 \\
\hline Once a day & $20(33.3 \%)$ & $23(38.3 \%)$ & \\
\hline 2 to 3 times a day & $40(66.6 \%)$ & $37(61.6 \%)$ & \\
\hline Level of collaboration in oral hygiene procedures & & & $<0.001$ \\
\hline High prior to orthodontic treatment & $36(60.0 \%)$ & $1(1.6 \%)$ & \\
\hline High from the start of orthodontic treatment & $16(26.6 \%)$ & $9(15.0 \%)$ & \\
\hline Low & $8(13.3 \%)$ & $50(83.3 \%)$ & \\
\hline Adaptation to removable appliance* & & & 0.019 \\
\hline She/he did not tolerate the appliance & $5(11.9 \%)$ & $0(0 \%)$ & \\
\hline She/he adapted to the appliance after some time & $7(16.6 \%)$ & $3(6.1 \%)$ & \\
\hline She/he adapted to the appliance immediately & $30(71.4 \%)$ & $46(93.8 \%)$ & \\
\hline Adaptation to fixed appliance & & & 0.026 \\
\hline She/he did not tolerate the appliance & $2(3.3 \%)$ & $0(0 \%)$ & \\
\hline She/he adapted to the appliance after some time & $3(5.0 \%)$ & $0(0 \%)$ & \\
\hline She/he adapted to the appliance immediately & $55(91.6 \%)$ & $60(100 \%)$ & \\
\hline Most difficult orthodontic phase & & & $<0.001$ \\
\hline Removable phase & $16(26.6 \%)$ & $22(36.6 \%)$ & \\
\hline Fixed phase & $16(26.6 \%)$ & $30(50.0 \%)$ & \\
\hline Removable extraoral phase & $6(10.0 \%)$ & $8(13.3 \%)$ & \\
\hline None of the above & $22(36.6 \%)$ & $0(0 \%)$ & \\
\hline Aspects found particularly overwhelming & & & $<0.001$ \\
\hline Insertion of the device each day & $5(8.3 \%)$ & $9(15.0 \%)$ & \\
\hline Taking care of treatment & $1(1.6 \%)$ & $0(0 \%)$ & \\
\hline Maintenance of oral hygiene & $28(46.6 \%)$ & $51(85.0 \%)$ & \\
\hline None of the above & $26(43.3 \%)$ & $0(0 \%)$ & \\
\hline
\end{tabular}

*This question was only answered by parents of disabled and healthy children who wore removable appliances $(n=42$ and $n=39$, respectively).

in those patients with the greatest differences between pre-treatment and post-treatment PAR scores $(P<0.01)$.

When parents were asked if they would allow their children to undergo similar treatments in the future, if required, 93.9\% of DCh parents and $90.0 \%$ of $\mathrm{HCh}$ parents responded positively.

All these results related to "Satisfaction and improvements" are detailed in Table 5 . 
Table 3 Benefits of orthodontic treatment as perceived by parents of disabled $(n=60)$ and healthy children ( $n=60)$

\begin{tabular}{|c|c|c|c|}
\hline & $\begin{array}{l}\text { Disabled children } \\
\text { n (\%) }\end{array}$ & $\begin{array}{l}\text { Healthy children } \\
\text { n (\%) }\end{array}$ & $P$ value \\
\hline $\begin{array}{l}\text { You wish to enhance } \\
\text { the appearance of } \\
\text { the teeth and face }\end{array}$ & & & 0.228 \\
\hline A lot & $41(68.3 \%)$ & 30 (50.0\%) & \\
\hline A little & $12(20.0 \%)$ & 19 (31.6\%) & \\
\hline Not concerned & $7(11.6 \%)$ & $11(18.3 \%)$ & \\
\hline $\begin{array}{l}\text { Improvement in } \\
\text { quality of life }\end{array}$ & & & 0.536 \\
\hline Yes & $50(83.3 \%)$ & $47(78.3 \%)$ & \\
\hline No & $4(6.6 \%)$ & $6(10.0 \%)$ & \\
\hline Don't know & $6(10.0 \%)$ & $8(13.3 \%)$ & \\
\hline $\begin{array}{l}\text { Improvement in } \\
\text { social acceptance }\end{array}$ & & & 0.016 \\
\hline Yes & 47 (78.3\%) & $33(55.0 \%)$ & \\
\hline No & $7(11.6 \%)$ & $10(16.6 \%)$ & \\
\hline Don't know & $6(10.0 \%)$ & $17(28.3 \%)$ & \\
\hline $\begin{array}{l}\text { Improvement in } \\
\text { social integration }\end{array}$ & & & 0.006 \\
\hline Yes & $43(71.6 \%)$ & $33(55.0 \%)$ & \\
\hline No & $10(16.6 \%)$ & $6(10.0 \%)$ & \\
\hline Don't know & $7(11.6 \%)$ & $21(35.0 \%)$ & \\
\hline $\begin{array}{l}\text { Other reasons for } \\
\text { seeking treatment }\end{array}$ & & & 0.002 \\
\hline $\begin{array}{l}\text { To improve dental } \\
\text { health }\end{array}$ & $32(53.3 \%)$ & $45(75.0 \%)$ & \\
\hline $\begin{array}{l}\text { To improve } \\
\text { chewing }\end{array}$ & $15(25.0 \%)$ & $14(23.3 \%)$ & \\
\hline To improve speech & $13(21.6 \%)$ & $1(1.6 \%)$ & \\
\hline
\end{tabular}

\section{Discussion}

In our experience, OT may take longer to complete in DCh patients than in the general population due to the complexity of the malocclusions, the greater number of appointments required, and occasionally due to the temporary withdrawal of appliances (a consequence of traumatic lesions, gingival thickening, or poor oral hygiene). Motivation is a key factor in achieving good cooperation during OT [13]. In HCh undergoing OT it has been suggested that the level of motivation does not increase during the different phases of treatment and that it is conditioned by the presence of discomfort and by the degree of acceptance of the device; furthermore, parents are often significantly more motivated than their children for OT to be performed [16]. Disabled individuals usually receive continuous daily attention from motivated parents, who are willing to do everything possible to increase their child's well-being [13]. The DCh parents are often therefore willing to become members of
Table 4 Adverse effects of orthodontic treatment as perceived by parents of disabled $(n=60)$ and healthy children $(n=60)$

\begin{tabular}{|c|c|c|c|}
\hline & $\begin{array}{l}\text { Disabled children } \\
\text { n (\%) }\end{array}$ & $\begin{array}{l}\text { Healthy children } \\
\text { n (\%) }\end{array}$ & $P$ value \\
\hline Oral lesions & & & 0.473 \\
\hline Frequent & $5(8.3 \%)$ & $0(0 \%)$ & \\
\hline Occasional & 31 (51.6\%) & 31 (51.6\%) & \\
\hline No & $24(40.0 \%)$ & $29(48.3 \%)$ & \\
\hline $\begin{array}{l}\text { Alteration of } \\
\text { everyday oral } \\
\text { function }\end{array}$ & & & 0.179 \\
\hline Frequent & $2(3.3 \%)$ & $0(0 \%)$ & \\
\hline Occasional & $12(20.0 \%)$ & $9(15.0 \%)$ & \\
\hline No & $46(76.6 \%)$ & $51(85.0 \%)$ & \\
\hline $\begin{array}{l}\text { Increased salivary } \\
\text { secretion and/or } \\
\text { nausea }\end{array}$ & & & 0.008 \\
\hline Frequent & $3(5.0 \%)$ & $0(0 \%)$ & \\
\hline Occasional & $9(15.0 \%)$ & $3(5.0 \%)$ & \\
\hline No & 48 (80.0\%) & 57 (95.0\%) & \\
\hline
\end{tabular}

the orthodontic team [7]; this occurred in the present series, in which DCh parents had a significantly higher degree of motivation than $\mathrm{HCh}$ parents.

Inadequate oral hygiene can be the greatest obstacle to the success of OT [7,14]. Atassi et al. [17] in a series of healthy patients undergoing OT, found that $60 \%$ of them had poor oral hygiene, confirming the need to develop oral hygiene maintenance programs for application during OT. In the present series, over $80 \%$ of $\mathrm{HCh}$ parents stated that the level of collaboration in their child's oral hygiene was low. Waldman et al. [5] considered that the principal limitations to OT in physically and learning disabled patients were their lack of understanding of the need for good oral hygiene and their reduced ability to perform adequate hygiene techniques. However, in the present study, the frequency of toothbrushing before and during OT was similar in the study and control groups.

A high percentage of $\mathrm{HCh}$ report feeling less discomfort with removable orthodontic appliances than with fixed ones [18], although greater collaboration was required from patients during the fixed appliance phase [16]. Apart from rare exceptions that require the use of removable appliances in patients with intellectual disability [14], our findings coincided with the majority of authors who have stated that these patients tolerate fixed multibracket appliances better [6].

Becker et al. [14] suggested that the two problems most frequently detected during OT in DCh were the maintenance of adequate oral hygiene and difficulties in monitoring treatment. In our survey, most $\mathrm{HCh}$ parents 
Table 5 Level of satisfaction and appreciation of improvements by surveyed parents of disabled $(n=33)$ and healthy children $(n=60)$, after completion of orthodontic treatment

\begin{tabular}{|c|c|c|c|}
\hline & $\begin{array}{l}\text { Disabled children } \\
\text { n (\%) }\end{array}$ & $\begin{array}{l}\text { Healthy children } \\
\text { n (\%) }\end{array}$ & $P$ value \\
\hline $\begin{array}{l}\text { Satisfaction with the } \\
\text { results }\end{array}$ & & & 0.000 \\
\hline $\begin{array}{l}\text { Satisfied but with } \\
\text { excessive effort }\end{array}$ & $2(6.0 \%)$ & $0(0 \%)$ & \\
\hline Satisfied & 17 (51.5\%) & $54(90.0 \%)$ & \\
\hline $\begin{array}{l}\text { The results } \\
\text { exceeded } \\
\text { expectations }\end{array}$ & 14 (42.4\%) & $6(10.0 \%)$ & \\
\hline $\begin{array}{l}\text { Improvement in } \\
\text { patient's self-image }\end{array}$ & & & 0.228 \\
\hline None & $3(9.0 \%)$ & $3(5.0 \%)$ & \\
\hline $\begin{array}{l}\text { The child is not } \\
\text { satisfied with the } \\
\text { result }\end{array}$ & $1(3.0 \%)$ & $0(0 \%)$ & \\
\hline $\begin{array}{l}\text { The child is pleased } \\
\text { with the result }\end{array}$ & $29(87.8 \%)$ & 57 (95.0\%) & \\
\hline $\begin{array}{l}\text { Reaction of family } \\
\text { and friends }\end{array}$ & & & $<0.001$ \\
\hline No reaction & $6(18.1 \%)$ & $43(71.6 \%)$ & \\
\hline $\begin{array}{l}\text { They encouraged us } \\
\text { throughout the } \\
\text { treatment }\end{array}$ & 9 (27.2\%) & $6(10.0 \%)$ & \\
\hline They got excited & $18(54.5 \%)$ & $11(18.3 \%)$ & \\
\hline $\begin{array}{l}\text { Improvement in } \\
\text { patient daily } \\
\text { activities }\end{array}$ & & & $<0.001$ \\
\hline No change & $5(15.1 \%)$ & $40(66.6 \%)$ & \\
\hline $\begin{array}{l}\text { Progress was } \\
\text { significant }\end{array}$ & $1(3.0 \%)$ & $14(23.3 \%)$ & \\
\hline $\begin{array}{l}\text { There was a very } \\
\text { marked improvement }\end{array}$ & $27(81.8 \%)$ & $6(10.0 \%)$ & \\
\hline $\begin{array}{l}\text { Change in patient's } \\
\text { social life }\end{array}$ & & & $<0.001$ \\
\hline None & $9(27.2 \%)$ & $34(56.6 \%)$ & \\
\hline $\begin{array}{l}\text { Slightly improved } \\
\text { social life }\end{array}$ & 9 (27.2\%) & $23(38.3 \%)$ & \\
\hline $\begin{array}{l}\text { Significantly } \\
\text { improved social life }\end{array}$ & 15 (45.4\%) & $3(5.0 \%)$ & \\
\hline $\begin{array}{l}\text { The child is ready to } \\
\text { undergo orthodontic } \\
\text { treatment in the } \\
\text { future, if needed }\end{array}$ & & & 0.711 \\
\hline Yes & 31 (93.9\%) & 54 (90.0\%) & \\
\hline No & $2(6.0)$ & $6(10.0 \%)$ & \\
\hline
\end{tabular}

found maintaining oral hygiene stressful; this was less common among the DCh parents. Parents actively involved in the day-to-day care of a child's well-being are highly motivated when seeking OT [7], which may explain why more than $40 \%$ of surveyed DCh parents did not find any phase of OT an overwhelming problem.

In some published series it has been found that over $90 \%$ of $\mathrm{HCh}$ undergoing OT and their parents were concerned about aesthetic appearance and that this was the main reason for requesting OT [19]. Al-Sarhad et al. [15] concluded that parents of sensory impaired children (blind and deaf) were aware of their child's dental aesthetic appearance and that this had a determining role in seeking OT. In physical and learning disabled patients, improved facial appearance has also been reported as the most common reason to request OT [13]. In the present series we did not observe statistically significant differences between the percentage of DCh and HCh parents for whom enhancing the facial appearance of their children was important.

Results of surveys conducted in healthy children undergoing OT revealed that both parents and children felt that an aesthetically pleasing result was important for psychosocial well-being [20]. Improved physical appearance and oral function following OT could increase the quality of life of DCh and promote their social acceptance [13]. This could explain the improvement in social relationships of DCh observed in the present series. However, in previous studies, parents have expressed their difficulty in appreciating these improvements, particularly in patients unable to express their feelings [21].

Becker et al. [13] showed that OT in DCh could not only improve the facial appearance but also masticatory function, speech and drooling control. In a survey performed on Swedish parents of DCh, the improvement in chewing and speech and the reduction of dental trauma were considered the principal benefits of OT [21]. In the present study, parents also requested OT for reasons related to orofacial function, as may be appreciated by the remarkable difference observed in speech improvement in DCh compared with HCh.

It has been shown that OT carries an increased risk of oral mucosal lesions in healthy individuals aged between 6 and 18 years, with gingival inflammation, erosion, ulceration and contusion being the most common findings [22]. In some DCh, such as those with Down's syndrome, oral ulcers can be the most common complication during OT [11]. In the present series, more than half of $\mathrm{HCh}$ parents and $60 \%$ of DCh parents declared that their children had oral lesions arising from OT. It has been suggested that adequate oral hygiene instructions and the early treatment of oral lesions are important considerations to increase patient motivation and to complete OT successfully [22]. Pain and discomfort during OT also strongly affect treatment satisfaction [23]. As for the disruption of daily functions during OT, Stewart et al. [18] reported that speech and swallowing disorders appeared in patients wearing removable appliances, and that these persisted in 
some cases even after 3 months. In the present series, over $75 \%$ of DCh parents and $85 \%$ of $\mathrm{HCh}$ parents confirmed that OT did not cause any alteration in everyday oral functions. However, a significantly higher percentage of DCh than $\mathrm{HCh}$ controls presented increased salivary secretion and/or nausea during OT.

In a study conducted on healthy adolescents who had received OT, it was found that only $34 \%$ were completely satisfied with results, $62 \%$ were relatively satisfied and $4 \%$ were dissatisfied [24]. These findings contrast with those described by Becker et al. [13] in a series of DCh in which $100 \%$ of parents surveyed said they felt satisfied with results, and $11 \%$ even said their expectations had been exceeded. In the present series, over $90 \%$ of DCh parents were satisfied, and over $40 \%$ stated that OT outcomes had exceeded their expectations; $100 \%$ of $\mathrm{HCh}$ parents stated they were satisfied with the outcome. These findings in both DCh and HCh may be related to other recently suggested factors conditioning satisfaction with OT outcome, such as quality of care and attention [23]. In a series published by Becker et al. [13], 63\% of DCh parents noted positive changes in their child's oral function after OT. In our series, the perception of improvement in daily activities and in the perceived changes in social life was significantly higher in DCh than in $\mathrm{HCh}$. These improvements will lead to greater self-confidence and satisfaction, and the parents of DCh would therefore allow their children to undergo the same treatment in the future, should it be necessary. Similarly, DCh parents surveyed by Becker et al. [13] would recommend OT to other patients and they would repeat the same procedure should the initial circumstances recur.

This study has certain limitations that must be taken into account, as they may potentially affect the results of the survey. The characteristics of the DCh group meant that their parents answered the questionnaire, and their motivation and expectations may have been exaggerated. The degree of patient collaboration is implicit in the inclusion criteria, as OT is indicated primarily in cooperative patients. The PAR index score had an impact on certain responses, particularly those relating to the degree of satisfaction and appreciation of improvement; as very severe malocclusions, such as those requiring surgical management, were excluded, we do not know if the replies would have been different in patients with higher PAR index scores. Finally, some functional variables, such as the improvement in patient daily activities, were evaluated on a qualitative basis and would benefit from a more objective assessment.

\section{Conclusions}

The results of this study confirm that parents of DCh undergoing OT show a high level of motivation and that they are willing to collaborate in oral hygiene procedures.
OT can produce a considerable improvement in quality of life, social relationships and oral function in DCh. The perceived level of satisfaction is often very high and parents of these children stated that they would repeat OT, if needed, in the future.

\section{Additional file}

Additional file 1: Spanish version of the survey.

\section{Abbreviations}

OT: Orthodontic treatment; DCh: Disabled children; HCh: Healthy children.

\section{Competing interests}

The authors report no declarations of interest.

\section{Authors' contributions}

MTA, EP, JS-R and IR performed the orthodontic treatment. MO and JL designed and applied the survey. MD analyzed data and drafted the manuscript. PD conceptualized the study and drafted the manuscript. All authors provided comments on the original draft and contributed to the development of the final draft. All authors read and approved the final manuscript.

\section{Acknowledgements}

To Dr. I Tomás for her technical assistance in the study design and drafting of the manuscript.

\section{Author details}

${ }^{1}$ Department of Paediatric Dentistry, School of Medicine and Dentistry, Santiago de Compostela University, Santiago de Compostela, Spain. ${ }^{2}$ OMEQUI Research Group, Santiago de Compostela University, Santiago de Compostela, Spain. ${ }^{3}$ Department of Orthodontics, School of Medicine and Dentistry, Santiago de Compostela University, Santiago de Compostela, Spain. ${ }^{4}$ Special Needs Unit, School of Medicine and Dentistry, Santiago de Compostela University, Santiago de Compostela, Spain.

Received: 26 March 2014 Accepted: 21 July 2014

Published: 5 August 2014

\section{References}

1. American Dental Association. Council on Dental Education: Find a Dentist: Specialty Definition (adopted April 2003). www.ada.org/2555.aspx. Accessed 10 January 2014.

2. Dinesh Rao B, Arnitha Hedge M, Munshi AK: Malocclusion and orthodontic treatment need of handicapped individuals in South Canara, India. Int Dent J 2003, 53:13-18.

3. Winter K, Baccaglini L, Tomar S: A review of malocclusion among individuals with mental and physical disabilities. Spec Care Dent 2008, 28:19-26.

4. Chaushu S, Becker A: Behaviour management needs for orthodontic treatment of children with disabilities. Eur J Orthod 2000, 22:143-149.

5. Waldman HB, Perlman SP, Swerdloff M: Orthodontics and the population with special needs. Am J Orthod Dentofacial Orthop 2000, 118:14-17.

6. Hobson RS, Nunn JH, Cozman I: Orthodontic management of orofacial problems in young people with impairments: review of the literature and case reports. Int J Ped Dent 2005, 15:355-363.

7. Becker A, Shapira J, Chaushu S: Orthodontic treatment for the special needs child. Progr Orthod 2009, 10:34-47.

8. Chadwick SM, Asher-McDade C: The orthodontic management of patients with profound learning disability. Br J Orthod 1997, 24:117-125.

9. Becker A, Shapira J: Orthodontic for the handicapped child. Eur J Orthod 1996, 18:55-67.

10. Kleint G, Kanitz G, Harzer W: Orthodontic treatment in handicapped children: report of four cases. J Dent Child 2002, 69:31-38.

11. Outumuro M, Abeleira MT, Caamaño F, Limeres J, Suarez D, Diz P, Tomás I: Maxillary expansion therapy in children with down syndrome. Ped Dent 2010, 32:499-504. 
12. Pratelli P, Gelbier S, Gibbons DE: Parental perception and attitudes on orthodontic care. Br J Orthod 1998, 25:41-46.

13. Becker A, Shapira J, Chaushu S: Orthodontic treatment for disabled children: motivation, expectation and satisfaction. Eur J Orthod 2000, 22:151-158.

14. Becker A, Shapira J, Chaushu S: Orthodontic treatment for disabled children-a survey of patient and appliance management. J Orthod 2001, 28:39-44.

15. Al-Sarheed M, Raman B, Nigel PH: The views and attitudes of parents of children with sensory impairment towards orthodontic care. Eur $J$ Orthod 2004, 26:87-91.

16. Adam SD, Jason D, Inglehart MS, Inglehart MR: Orthodontic treatment motivation and cooperation: a cross-sectional analysis of adolescent patients' and patients' responses. Am J Orthod Dentofacial Orthop 2009, 136:780-787.

17. Atassi F, Awartani F: Oral hygiene status among orthodontic patients. J Contemp Dent Pract 2010, 11:25-32.

18. Stewart FN, Kerr WJ, Taylor JS: Appliance wear: the patient's point of view. Eur J Orthod 1997, 19:377-382.

19. Daniels AS, Seacat JD, Inglehart MR: Orthodontic treatment motivation and cooperation: a cross-sectional analysis of adolescent patients' and patients' responses. Am J Orthod Dentofacial Orthop 2009, 136:780-787.

20. Birkeland K, Boe OE, Wisth PJ: Relationship between occlusion and satisfaction with dental appearance in orhodontically treated and untreated groups: a longitudinal study. Eur J Orthod 2000, 22:509-518.

21. Trulsson U, Klingberg G: Living with a child with a severe orofacial handicap: experiences from the perspectives of parents. Eur J Oral Sci 2003, 111:19-25.

22. Baricevic M, Mravak-Stipetic M, Majstorovic M, Baranovic M, Baranovic D, Loncar B: Oral mucosal lesions during orthodontic treatment. Int J Paed Dent 2011, 21:96-102.

23. Feldmann I: Satisfaction with orthodontic treatment outcome. Angle Orthod 2014, doi:10.2319/093013-710.1.

24. Anderson LE, Arruda A, Inglehart MR: Adolescent patients' treatment motivation and satisfaction with orthodontic treatment: do possible selves matter? Angle Orthod 2009, 79:821-827.

doi:10.1186/1472-6831-14-98

Cite this article as: Abeleira et al:: Orthodontic treatment for disabled children: a survey of parents' attitudes and overall satisfaction. BMC Oral Health 2014 14:98.

\section{Submit your next manuscript to BioMed Central and take full advantage of:}

- Convenient online submission

- Thorough peer review

- No space constraints or color figure charges

- Immediate publication on acceptance

- Inclusion in PubMed, CAS, Scopus and Google Scholar

- Research which is freely available for redistribution 